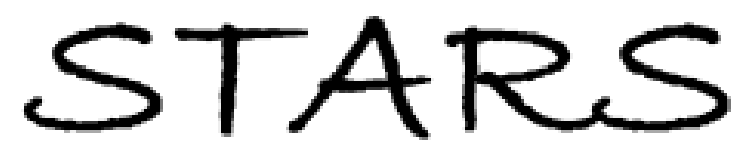

University of Central Florida

STARS

$1-1-2002$

\title{
Comparative evaluation of protective coatings and focused ion beam chemical vapor deposition processes
}

B. W. Kempshall

University of Central Florida

L. A. Giannuzzi

University of Central Florida

B. I. Prenitzer

F. A. Stevie

S. X. Da

Find similar works at: https://stars.library.ucf.edu/facultybib2000

University of Central Florida Libraries http://library.ucf.edu

This Article is brought to you for free and open access by the Faculty Bibliography at STARS. It has been accepted for inclusion in Faculty Bibliography 2000s by an authorized administrator of STARS. For more information, please contact STARS@ucf.edu.

\section{Recommended Citation}

Kempshall, B. W.; Giannuzzi, L. A.; Prenitzer, B. I.; Stevie, F. A.; and Da, S. X., "Comparative evaluation of protective coatings and focused ion beam chemical vapor deposition processes" (2002). Faculty Bibliography 2000s. 3282.

https://stars.library.ucf.edu/facultybib2000/3282

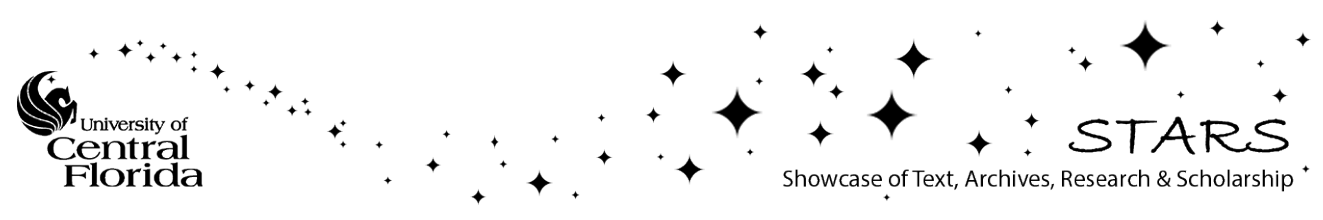




\section{Comparative evaluation of protective coatings and focused ion beam chemical vapor deposition processes}

B. W. Kempshall, L. A. Giannuzzi, B. I. Prenitzer, F. A. Stevie, and S. X. Da

Citation: Journal of Vacuum Science \& Technology B: Microelectronics and Nanometer Structures Processing, Measurement, and Phenomena 20, 286 (2002); doi: 10.1116/1.1445165

View online: https://doi.org/10.1116/1.1445165

View Table of Contents: https://avs.scitation.org/toc/jvn/20/1

Published by the American Institute of Physics

\section{ARTICLES YOU MAY BE INTERESTED IN}

Preparation of transmission electron microscopy cross-section specimens using focused ion beam milling Journal of Vacuum Science \& Technology A 19, 2186 (2001); https://doi.org/10.1116/1.1378072

Focused ion beam induced deposition of platinum Journal of Vacuum Science \& Technology B: Microelectronics Processing and Phenomena 8, 1826 (1990); https://doi.org/10.1116/1.585167

High brightness inductively coupled plasma source for high current focused ion beam applications Journal of Vacuum Science \& Technology B: Microelectronics and Nanometer Structures Processing, Measurement, and Phenomena 24, 2902 (2006); https://doi.org/10.1116/1.2366617

Comprehensive study of focused ion beam induced lateral damage in silicon by scanning probe microscopy techniques

Journal of Vacuum Science \& Technology B 28, 595 (2010); https://doi.org/10.1116/1.3431085

Focused ion beam induced deposition of platinum for repair processes

Journal of Vacuum Science \& Technology B: Microelectronics and Nanometer Structures Processing, Measurement, and Phenomena 9, 162 (1991); https://doi.org/10.1116/1.585279

Three-dimensional nanostructure fabrication by focused-ion-beam chemical vapor deposition Journal of Vacuum Science \& Technology B: Microelectronics and Nanometer Structures Processing, Measurement, and Phenomena 18, 3181 (2000); https://doi.org/10.1116/1.1319689 


\title{
Comparative evaluation of protective coatings and focused ion beam chemical vapor deposition processes
}

\author{
B. W. Kempshall ${ }^{\text {a) }}$ and L. A. Giannuzzi \\ Department of Mechanical, Materials, and Aerospace Engineering, University of Central Florida, \\ P.O. Box 162450, 4000 Central Florida Blvd., Orlando, Florida 32816-2450 \\ B. I. Prenitzer and F. A. Stevie \\ Agere Systems (Cirent Semiconductor), 9333 S. John Young Parkway, Orlando, Florida 32819 \\ S. X. Da \\ FEI Company, 7451 NW Evergreen Parkway, Hillsboro, Oregon 97124-5830
}

(Received 18 April 2001; accepted 26 November 2001)

\begin{abstract}
Dual-beam instruments incorporate both an electron column and an ion column into a single instrument, and therefore allow the chemical vapor deposition (CVD) process to be either ion- or electron-beam assisted. Damage has been observed in the surface layers of specimens in which ion-beam assisted CVD processes have been employed. Cross-section transmission electron microscopy (TEM) has been used to compare (100) Si substrates on which Pt metal lines have been grown by ion- and electron-beam assisted CVD processes. The micrographs show that a $30 \mathrm{keV}$ $\mathrm{Ga}^{+}$ion beam, a $5 \mathrm{keV}$ ion beam, and a $3 \mathrm{keV}$ electron beam imparts $50 \mathrm{~nm}, 13 \mathrm{~nm}$, and $3 \mathrm{~nm}$ of damage to the $\mathrm{Si}$ substrate, respectively. In addition, $\mathrm{Au}-\mathrm{Pd}$ and $\mathrm{Cr}$ sputter coatings were evaluated for the prevention of ion-beam induced surface damage. TEM cross-section specimens revealed that Cr sputter coatings $>30 \mathrm{~nm}$ in thickness are sufficient to protect the (100) Si surface from the 30 $\mathrm{keV} \mathrm{Ga}^{+}$ion beam while $\mathrm{Au}-\mathrm{Pd}$ sputter coatings up to $70 \mathrm{~nm}$ in thickness may be discontinuous and, therefore, will not protect surface regions from ion beam damage. (C) 2002 American Vacuum Society. [DOI: 10.1116/1.1445165]
\end{abstract}

\section{INTRODUCTION}

Focused ion beam (FIB) instruments have become extremely useful as specimen preparation tools for transmission electron microscopy (TEM). ${ }^{1,2}$ More recently, the techniques developed for TEM have been extended to include specimen preparation for subsequent analysis in scanning electron microscopy, scanning transmission electron microscopy, secondary ion mass spectrometry, and scanning Auger microscopy. ${ }^{3}$ The introduction of dual-beam FIB systems, which include both an ion column and an electron column on the same platform, has afforded increased versatility to the FIB processes. The dual-beam instruments allow for the traditional FIB processes of imaging, milling, and chemical vapor deposition (CVD) with the ion column as well as imaging and CVD deposition with the electron column.

The ion column utilizes a finely focused ion beam from a $\mathrm{Ga}^{+}$liquid metal ion source to perform imaging, milling, and CVD operations. The interaction of the finely focused ion beam with the target material causes the ejection of secondary ions and secondary neutrals (which may be liberated as atoms, molecules, or clusters) and results in milling of the target material. The emitted secondary electrons or the secondary ions from the ion-beam-solid interaction may be utilized for imaging. The ion-beam assisted CVD process involves the introduction of organometallic gas molecules in the vicinity of the surface of the target material while the ion beam is rastered in a predefined pattern. The interaction be-

${ }^{a)}$ Electronic mail: bwk43981@ucf.edu tween the ion beam and the adsorbed organometallic molecules on the surface of the target material results in the net deposition of the metallic element (plus a considerable amount of carbon and $\mathrm{Ga}$ ) and the release of the volatile carbon based gas molecules as outlined in the schematic drawing shown in Fig. 1. ${ }^{4}$

The electron column on the dual-beam instrument can be used for imaging, just as in a traditional SEM, and for electron-beam assisted CVD. The mechanism for electronbeam assisted CVD is very similar to the previously described ion-beam assisted CVD process, but the deposition efficiency is much lower than for the ion-beam assisted CVD process. $^{5}$

The CVD metal layers may be used for device modification by depositing alternate paths of electrical conduction. ${ }^{6,7,8}$ Alternatively, these CVD layers may be used as a protective layer for subsequent milling operations in the FIB. ${ }^{1,2}$ Protection is especially critical for analysis of surface layers (e.g., ultrashallow regions of a specimen) or for the surface itself. Therefore it is important to investigate the possible damage that may occur during the CVD process in the FIB. The use of a single beam FIB for the preparation of TEM specimens may require coating the sample prior to insertion into the FIB to prevent spurious sputtering of the desired material in the region of interest during FIB imaging. Thus, it is prudent to investigate the efficacy of various protective sputter coatings (i.e., $\mathrm{Au}-\mathrm{Pd}$ and $\mathrm{Cr}$ ) that may be deposited onto a sample surface prior to insertion into the FIB instrument. 


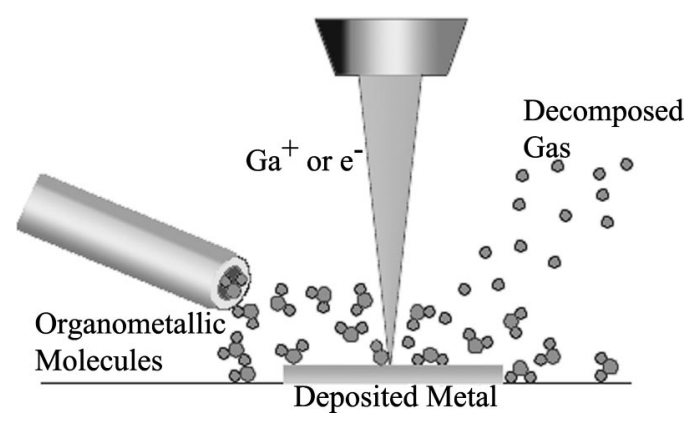

FIG. 1. Schematic drawing of the CVD process showing the introduction of organometallic molecules, decomposition of the molecules with either the $\mathrm{Ga}^{+}$ion or electron beam, and the net deposition of metal on the substrate.

\section{EXPERIMENT}

(100) Si wafers were used as the substrate for this investigation. An FEI XL830 dual-beam instrument with the electron beam operating at an accelerating voltage of $3 \mathrm{keV}$ and with a beam current of $300 \mathrm{pA}$ was used to grow an electronbeam assisted CVD Pt line. An FEI FIB 200 TEM operating at an accelerating voltage of $5 \mathrm{keV}$ with a $60 \mathrm{pA}$ beam current was used to deposit the $5 \mathrm{keV} \mathrm{Ga}{ }^{+}$ion-beam assisted CVD Pt line. An FEI FIB 800 operating at an accelerating voltage of $30 \mathrm{keV}$ with an $11 \mathrm{pA}$ beam current was used to deposit the $30 \mathrm{keV} \mathrm{Ga}^{+}$ion-beam assisted CVD Pt line. Care was taken to avoid imaging the regions of the $\mathrm{Si}$ wafer in which the Pt deposition would occur prior to the actual Pt CVD operation because imaging sputters the surface. The $\mathrm{Si}$ substrates containing the $\mathrm{Pt}$ lines were then covered with a sputter coated $\mathrm{Au}-\mathrm{Pd}$ layer using an Emitech K550 in order to preserve the integrity of the CVD Pt lines and to delineate the Pt lines from subsequent Pt depositions used for TEM specimen preparation of the samples. In addition, a Si substrate was sputter coated with a 70-nm-thick Au-Pd layer using an Emitech K550 and another Si substrate was sputter coated with a 60-nm-thick Cr sputter coating using an Emitech K675. All of the Si substrates were then inserted into the FEI FIB 200 TEM and the deposited lines and protective coatings were cross-sectioned for TEM analysis using the FIB lift out TEM specimen preparation technique ${ }^{1,2}$ as shown in Fig. 2. A Philips EM430 TEM operating at $300 \mathrm{keV}$ and an FEI Tecnai F30 TEM operating at $200 \mathrm{keV}$ with $\mathrm{x}$-ray energy dispersive spectrometry (XEDS) was used for the

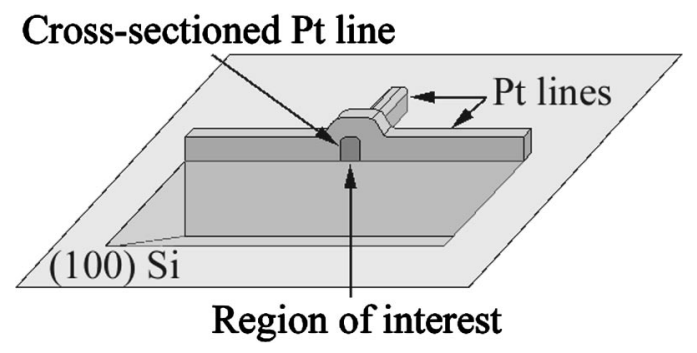

FIG. 2. Schematic drawing of a portion of the TEM FIB lift out specimen preparation technique showing the cross-sectioned Pt line that was deposited with either the $3 \mathrm{keV}$ electron beam, $5 \mathrm{keV} \mathrm{Ga}^{+}$ion beam, or the $30 \mathrm{keV}$ $\mathrm{Ga}^{+}$ion beam.

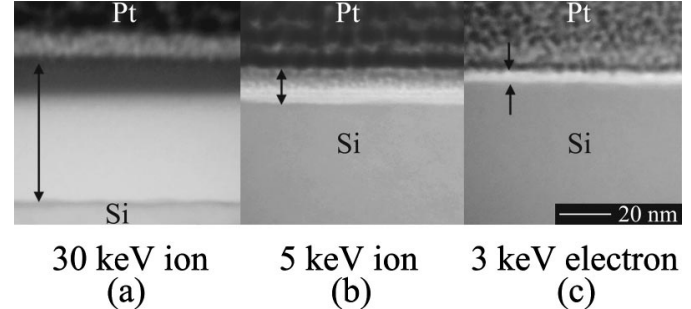

FIG. 3. Observed damage regions and corresponding damage depths (shown by arrows) from the TEM FIB-LO cross-sectioned Pt CVD lines as deposited by (a) $30 \mathrm{keV} \mathrm{Ga}{ }^{+}$ion beam- $50 \mathrm{~nm}$, (b) $5 \mathrm{keV} \mathrm{Ga}^{+}$ion beam-13 $\mathrm{nm}$, and (c) $3 \mathrm{keV}$ electron beam-3 nm. (The $\mathrm{nm}$ marker refers to all three images.)

TEM analysis. TRIM (Ref. 9) simulations were also used to generate comparative models of the anticipated ion damage for the cases of the 5 and $30 \mathrm{keV} \mathrm{Ga}{ }^{+}$ion deposition. The models are used to correlate the observed damage with the production of vacancies found with the TRIM (Ref. 9) simulations.

\section{RESULTS AND DISCUSSION}

A direct comparison of the damage that occurs during the CVD deposition using a $30 \mathrm{keV} \mathrm{Ga}^{+}$ion beam, a $5 \mathrm{keV} \mathrm{Ga}^{+}$ ion beam, and a $3 \mathrm{keV}$ electron beam is shown in Figs. 3(a), $3(\mathrm{~b})$, and 3(c). As is evident from the cross-section TEM images in Figs. 3(a) and 3(b) the 30 and $5 \mathrm{keV} \mathrm{Ga}^{+}$ion beam impart 50 and $13 \mathrm{~nm}$ of damage to the unprotected $\mathrm{Si}$ substrate during the Pt CVD process, respectively. The damage layer observed for the $30 \mathrm{keV} \mathrm{Ga}{ }^{+}$ion-beam assisted deposition is slightly larger, but in agreement with the $40 \mathrm{~nm}$ damage depths reported by Lipp et al. ${ }^{10}$ and Kato et al. ${ }^{11}$ as will be discussed below. The damage layer corresponds to the bright amorphous phase observed between the nanocrystalline Pt and the single crystal Si. Damage of this nature can have a severely adverse impact on the subsequent analysis of the surface layers and/or ultrashallow regions of dopant wafers. Figure 3(c) is a bright field TEM cross-section image of the Pt line that was deposited using the $3 \mathrm{keV}$ electron beam. The diffraction contrast observed in Fig. 3(c) indicates the presence of an apparent damage layer of $3 \mathrm{~nm}$. However, it should be noted that a native $\mathrm{SiO}_{2}$ layer due to $\mathrm{Si}$ oxidation in atmosphere is on the same order of thickness. ${ }^{12-14}$ Therefore, the $3 \mathrm{keV}$ electron beam assisted Pt deposition contributes little or no damage to the Si surface. Hence, if analysis of the surface layers or ultrashallow regions is desired, the electron beam Pt deposition for protecting the surface is a better option than the ion-beam Pt deposition.

A closer examination of the damage regions of the ionbeam assisted Pt deposition as shown in Figs. 4(a) and 4(b) reveals two interesting features. The first is that the TRIM (Ref. 9) simulated production of vacancies for the respective $30 \mathrm{keV}$ [Fig. 4(a)] and $5 \mathrm{keV}$ [Fig. 4(b)] $\mathrm{Ga}^{+}$ion beams correlates qualitatively with the empirically observed $40 \mathrm{~nm}$ and $13 \mathrm{~nm}$ amorphous damage region in each case, respectively. The continuous contrast variation in Fig. 4(b) is most likely due to ion damage and mixing of Pt into the amor- 


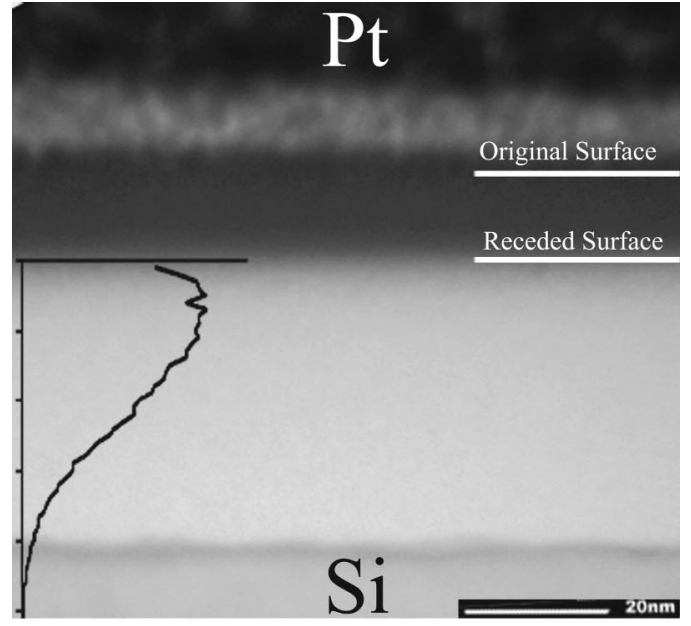

(a)

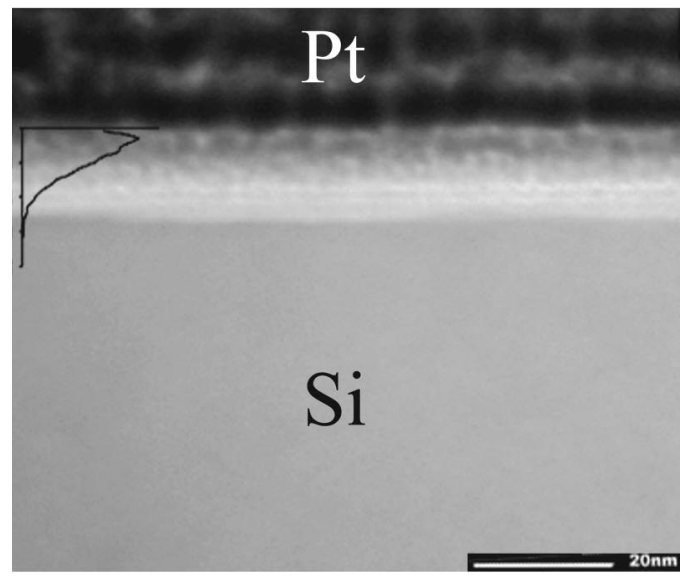

(b)

FIG. 4. Correlation of the TRIM simulated production of vacancies for (a) $30 \mathrm{keV} \mathrm{Ga}^{+}$and (b) $5 \mathrm{keV} \mathrm{Ga}^{+}$into Si. The micrograph in (a) shows the TRIM simulation plot beginning at the region believed to be the extent to which the Si surface receded during the early stages of the ion-beam assisted CVD process. (The same Si surface recession phenomenon is not readily apparent in the $5 \mathrm{keV}$ case.)

phous Si during the $\mathrm{Pt}$ deposition. The second interesting feature is that for the case of the $30 \mathrm{keV} \mathrm{Ga}^{+}$ion-beam assisted Pt deposition [Fig. 4(a)] there is an additional $10 \mathrm{~nm}$ damage layer between the Pt deposition and the amorphous region. In a lower magnification image of the $30 \mathrm{keV} \mathrm{Ga}^{+}$ ion-beam assisted deposition shown in Fig. 5, a dark band appears directly below the cross-sectioned Pt line and correspondingly shows a dip in the $\mathrm{Si}$ in the same region. The parallel lines drawn on the TEM micrograph extend from the adjacent areas of the Pt deposition and show that the Si surface has receded as a result of surface sputtering by the 30 $\mathrm{keV} \mathrm{Ga}^{+}$ion-beam assisted deposition. Using an FEI Tecnai F30 TEM with XEDS, it was determined that the dark band is a mixture of $\mathrm{Si}$ and Pt. Figure 6 shows an overlay of the normalized emitted $\mathrm{Pt} L \alpha / \mathrm{Si} K \alpha$ peak intensity ratio across the region affected during the early stages of the $30 \mathrm{keV} \mathrm{Ga}^{+}$ ion-beam assisted CVD process. The peak intensity ratio also corresponds with the mass-thickness contrast observed in the image, which further confirms the mixture of $\mathrm{Pt}$ and $\mathrm{Si}$ in the

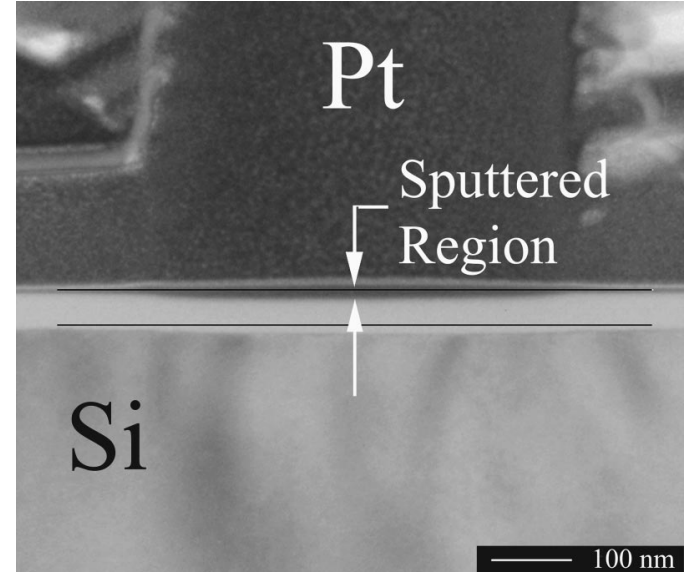

FIG. 5. Low magnification TEM micrograph of the cross-sectioned $30 \mathrm{keV}$ $\mathrm{Ga}^{+}$ion-beam assisted Pt CVD line. The region directly beneath the crosssectioned Pt line where the parallel lines have been drawn shows a dip in the substrate indicating that the Si surface was sputtered in the deposition process.

dark band. The lighter band just above the original surface in Fig. 6 is a diffuse region where the Pt deposition begins out of the sputtered and redeposited Pt and $\mathrm{Si}$. The dark band is thus the result of the competition between sputtering and deposition at the early stages of the ion-beam assisted CVD process. ${ }^{15,16}$ The observation of this layer is different from previous reports ${ }^{10,11}$ because a cross-section TEM specimen was prepared that included the entire region directly under the Pt line as well as the areas adjacent to the Pt line. The result is the observation of the total damage incurred from the CVD Pt deposition using $30 \mathrm{keV} \mathrm{Ga}^{+}$ions. The total thickness of the damage layer is $50 \mathrm{~nm}$, which consists of 40 $\mathrm{nm}$ of ion-beam damage (in agreement with Lipp et al. ${ }^{10}$ and Kato et al. ${ }^{11}$ ) plus $10 \mathrm{~nm}$ of damage in the form of the sputter eroded Si surface. The same phenomenon is not readily observed in the case of the $5 \mathrm{keV} \mathrm{Ga}^{+}$ion-beam assisted deposition, due to the much lower beam energy.

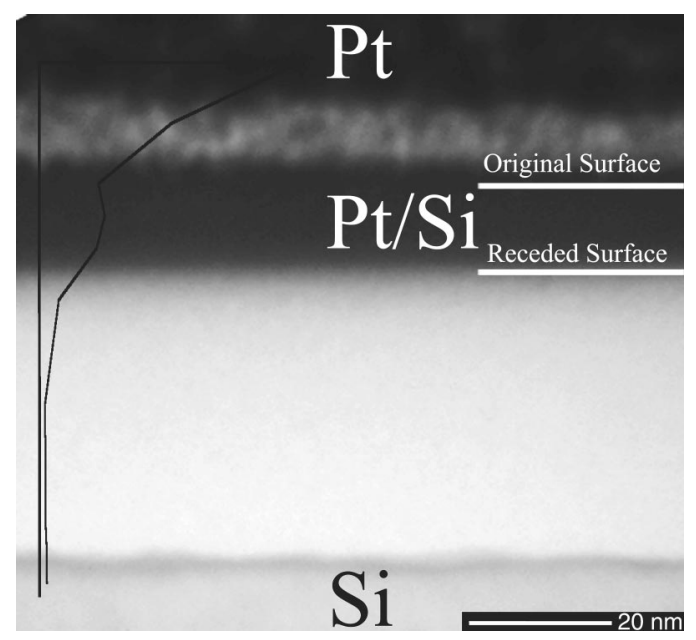

FIG. 6. Correlation of the emitted $\mathrm{Pt} L \alpha / \mathrm{Si} K \alpha$ peak intensity ratio with the observed mass-thickness contrast across the region affected during the early stages of the $30 \mathrm{keV} \mathrm{Ga}^{+}$ion-beam assisted CVD process. 


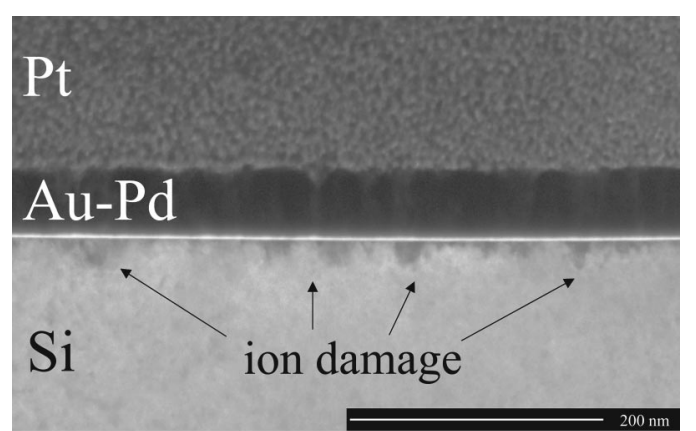

(a)

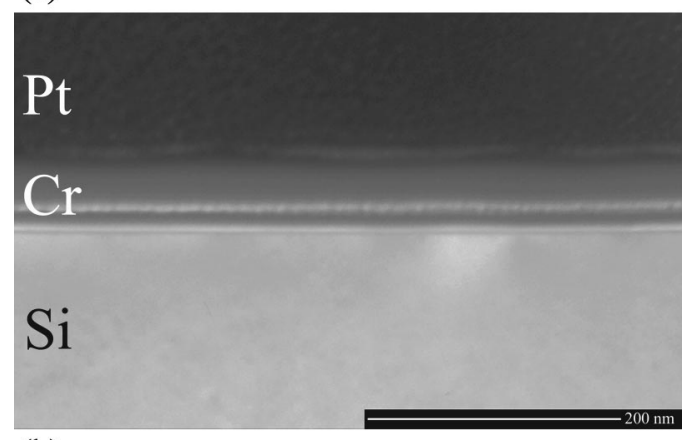

(b)

FIG. 7. Cross-section TEM micrographs showing the effectiveness of (a) $\mathrm{Au}-\mathrm{Pd}$ and (b) $\mathrm{Cr}$ sputter coatings as a protective layer against the $30 \mathrm{keV}$ $\mathrm{Ga}^{+}$ion-beam assisted Pt CVD process.

An alternative to electron-beam assisted Pt deposition, particularly for single beam FIB instruments, may be to protect the ultrashallow surface region with a low-energy sputter deposition. Figures 7(a) and 7(b) show cross-section TEM images of a $\mathrm{Si}$ substrate that was sputter coated with a 70nm-thick Au-Pd layer [Fig. 7(a)] and a 600-nm-thick $\mathrm{Cr}$ layer [Fig. 7(b)] prior to depositing a $30 \mathrm{keV} \mathrm{Ga}^{+}$ion-beam assisted CVD Pt layer. As shown in Fig. 7(b), the Cr coating completely protects the $\mathrm{Si}$ surface from the $30 \mathrm{keV} \mathrm{Ga}^{+}$ion beam during the Pt CVD deposition process. A TRIM (Ref. 9) simulation of $30 \mathrm{keV} \mathrm{Ga}^{+}$at $0^{\circ}$ incidence into $\mathrm{Cr}$ resulted in a modeled projected ion range of $11.4 \mathrm{~nm}$ with a straggle of $5.3 \mathrm{~nm}$. Thus, a 30-nm-thick Cr layer is sufficient to protect a substrate from $30 \mathrm{keV} \mathrm{Ga}^{+}$ions. Conversely, $\mathrm{Au}-\mathrm{Pd}$ deposits in an islandlike morphology as shown in Fig. 8. The plan view SEM micrograph in Fig. 8 shows a 40-nm-thick

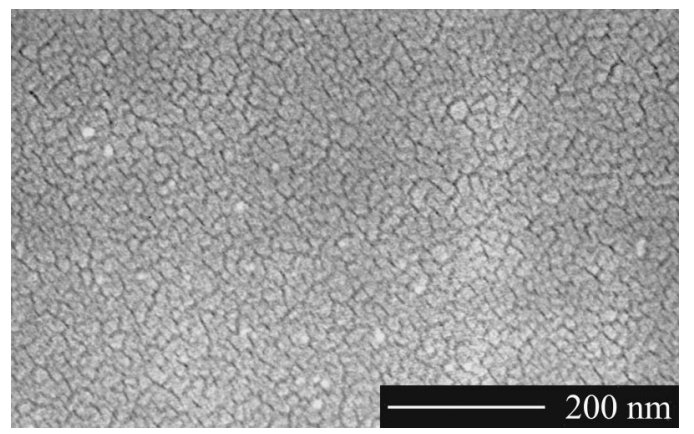

FIG. 8. Plan view SEM micrograph showing the islandlike morphology of $\mathrm{Au}-\mathrm{Pd}$ sputter coated on a (100) Si substrate at room temperature.
$\mathrm{Au}-\mathrm{Pd}$ sputter coating that was deposited on a Si substrate using the same Emitech K550 system. The average island size is about $50 \mathrm{~nm}$, which is consistent with the size of the islands in the TEM cross section in Fig. 7(a). The crosssection TEM image in Fig. 7(a) shows alternating regions of light and dark contrast separating the islands. The mottled contrast corresponds to the ion damage regions in the substrate where the $\mathrm{Pt} / \mathrm{Ga}$ beam mixture penetrated down the island walls and into the Si. TRIM (Ref. 9) simulations of 30 $\mathrm{keV} \mathrm{Ga}^{+}$at $0^{\circ}$ incidence into $\mathrm{Au}-\mathrm{Pd}$ resulted in a modeled projected range of $9.4 \mathrm{~nm}$ with a straggle of $5.4 \mathrm{~nm}$. Thus, 70 $\mathrm{nm}$ of $\mathrm{Au}-\mathrm{Pd}$ should be sufficient to prevent substrate damage. However, the observed discontinuous $\mathrm{Au}-\mathrm{Pd}$ coating is ineffective at completely protecting an entire surface from radiation damage during ion-beam assisted CVD. Based on the observations presented, $\mathrm{Cr}$ is a more effective barrier for protecting ultrashallow surface regions from the FIB deposition (or milling) processes.

\section{SUMMARY}

The preservation of surface integrity afforded to samples subjected to FIB milling or deposition operations is important to quantify. It has been shown that electron-beam assisted Pt CVD results insignificantly less, and possibly no surface damage as compared to ion-beam assisted Pt CVD in the FIB. Using a $3 \mathrm{kV}$ electron beam a $3 \mathrm{~nm}$ amorphous interface layer is observed between the nanocrystalline $\mathrm{Pt}$ and the monocrystalline $\mathrm{Si}$ substrate. Using the $\mathrm{Ga}^{+}$ion beam for the Pt CVD process resulted in a $13 \mathrm{~nm}$ damage layer when deposition was performed with a $5 \mathrm{kV} \mathrm{Ga}^{+}$ion beam and a $50 \mathrm{~nm}$ damage layer when deposition was performed with a $30 \mathrm{kV} \mathrm{Ga}^{+}$ion beam. The $50 \mathrm{~nm}$ damage layer consisted of $10 \mathrm{~nm}$ of erosion damage and $40 \mathrm{~nm}$ of ion-beam damage into the Si substrate. In addition, the depth of ion damage in Si correlates qualitatively with the simulated production of vacancies generated by TRIM simulations for both the 5 and the $30 \mathrm{keV} \mathrm{Ga}^{+}$ion beams. The viability of a low-energy sputter coating procedure to deposit a layer of protective material prior to FIB milling or deposition was investigated. It was found that a $\mathrm{Cr}$ sputter coated layer greater than $30 \mathrm{~nm}$ in thickness is sufficient to protect a Si surface from a $30 \mathrm{kV} \mathrm{Ga}^{+}$ion beam (or electron beam). It has also been determined that the $\mathrm{Au}-\mathrm{Pd}$ sputter coated layers up to a thickness of $70 \mathrm{~nm}$ are discontinuous and therefore are ineffective at protecting surface regions from ionbeam damage.

\section{ACKNOWLEDGMENTS}

This work was made possible through the generous support of Cirent Semiconductor, the I4 /UCF/Cirent Partnership, AMPAC, and NSF DMR Award 9703281. The authors would also like to especially thank FEI Company and Micro Optics Inc. for the use of their equipment.

${ }^{1}$ R. Young, E. C. G. Kirk, D. A. Williams, and H. Ahmed, Mater. Res. Soc. Symp. Proc. 205, 199 (1990)

${ }^{2}$ L. A. Giannuzzi and F. A. Stevie, Micron 30, 197 (1999). 
${ }^{3}$ F. A. Stevie, C. B. Vartulli, R. H. Mills, R. B. Irwin, T. L. Shofner, and L. A. Giannuzzi, Proceedings of Microscopy and Microanalysis 1999, Portland, OR 1-5 August 1999, Vol. 5, Suppl., pp. 888-889; Surface Interface Anal. (to be published).

${ }^{4}$ A. D. Dubner, A. Wagner, J. Melngailis, and C. V. Thompson, J. Appl. Phys. 70, 665 (1991).

${ }^{5}$ S. Lipp, L. Frey, C. Lehrer, B. Frank, E. Demm, S. Pauthner, and H. Ryssel, J. Vac. Sci. Technol. B 14, 3920 (1996).

${ }^{6}$ L. R. Harriott, Appl. Surf. Sci. 36, 432 (1989).

${ }^{7}$ F. C. van den Heuvel, M. H. F. Overwijk, E. M. Fleuren, H. Laisina, and K. J. Sauer, Microelectron. Eng. 21, 209 (1993).

${ }^{8}$ J. Melngailis, Proc. SPIE 1465, 36 (1991).

${ }^{9}$ J. F. Ziegler and J. P. Biersack, computer code TRIM (http:// www.research.ibm.com/ionbeams/home.htm\#SRIM, IBM-Research,
Yorktown, NY, 1998).

${ }^{10}$ S. Lipp, L. Frey, C. Lehrer, B. Frank, E. Demm, and H. Ryssel, J. Vac. Sci. Technol. B 14, 3996 (1996).

${ }^{11}$ N. I. Kato, N. Miura, and N. Tsutsui, J. Vac. Sci. Technol. A 16, 1127 (1998).

${ }^{12}$ I. Eisele, Appl. Surf. Sci. 36, 39 (1989).

${ }^{13}$ P. S. Lee, D. Mangelinck, K. L. Pey, J. Ding, J. Y. Dai, C. S. Ho, and A. See, Microelectron. Eng. 51-52, 583 (2000).

${ }^{14}$ M. Rebien, W. Henrion, H. Angermann, and A. Roseler, Surf. Sci. 462, 143 (2000).

${ }^{15}$ M. H. F. Overwijk and F. C. van den Heuvel, Nucl. Instrum. Methods Phys. Res. B 80/81, 1324 (1993).

${ }^{16}$ J. S. Ro, C. V. Thompson, and J. Melngailis, J. Vac. Sci. Technol. B 12, 73 (1994). 